\title{
SAUDAÇÃO AO PROFESSOR CARLOS DA SILVA LACAZ*
}

\author{
Yoriko Kamiyama**
}

\section{Caro homenageado Professor Doutor Carlos da Silva Lacaz,}

A Escola de Enfermagem da Universidade de São Paulo está em festa neste dia em que, a douta Congregação, em sessão solene, inaugura o Retrato do Professor Doutor Carlos da Silva Lacaz, eminente médico, grande mestre da ciência contemporânea no cenário nacional e internacional, que prestigiou esta Escola, dirigindo-a durante 4 anos, de 1978 a 1982.

Quisera, antes, colorir minhas palavras com os magnificos e rutilantes talentos do homenageado para que esta saudação tecesse à altura, o reconhecimento da Escola de Enfermagem para cujo engrandecimento muito tem contribuido.

Recebendo, todavia, impelida pela circunstância, a honrosa incumbência de, em nome da Congregação da Escola de Enfermagem, saudar esta grande personalidade que é o Professor Doutor Carlos da Silva Lacaz, usarei de um instrumento menos valioso para suprir o melhor, e para fazê-lo, certa que tenho o perdão do ilustre homenageado e a compreensão de todos.

Professor Doutor Carlos da Silva Lacaz, natural de Guaratinguetá, graduou-se pela Faculdade de Medicina da Universidade de São Paulo, em 1940, ingressando em seguida, na carreira universitária.

Dotado de raras qualidades intelectuais, morais e humanisticas, ainda estudante, começou a se dedicar às atividades científico-culturais e assistenciais do Centro Acadêmico Oswaldo $\mathrm{Cruz}$, tendo inclusive renovado a Revista de Medicina editada por aquele órgão estudantil. No Curso de Medicina, sempre se classificou em $1^{\circ}$ lugar, fazendo jus, entre outros, ao "Prêmio Rockfeller" e "Prêmio La Royale", outorgados respectivamente, ao aluno melhor classificado nas Cadeiras Básicas e em todo o Curso.

Tantas e tão altas qualidades o predestinavam para o papel que veio a desempenhar na comunidade acadêmica brasileira e mundial.

- Discurso pronunciado na Escola de Enfermagem da USP, no dia 12 de junho de 1985, por ocasiăo da inauguraç̃o do retrato do Professor Carlos da silva Lacaz.

** Enfermeira. Professor titular do Departamento de Enformagem médico-Cirárzica da Inscola de Enfermagem da USP - disciplina Innfermagom om Doengas Transmisofivels. Vice-Diretora da Hiscola de Enfermagem da USP. 
Galgou rapidamente todos os degrau da carreira docente na Universidade de São Paulo, sempre com distinção, conquistando já em 1953, a Cátedra de Microbiologia e Imunologia da Faculdade de Medicina.

Especialista em Doenças Transmissiveis, Pioneiro da Micologia Médica, Imunopatologia, Iatrofarmacogenia, Geografia Médica, Tropicologia Médica, fundou em 1959 o Instituto de Medicina Tropical de São Paulo, onde exerce atualmente o cargo de Diretor.

E membro da Academia Nacional de Medicina, à qual tem acesso somente figuras exponenciais, de méritos incomuns.

$\mathrm{Na}$ expressiva produção científica com que tem contribuido, o eminente Professor, no progresso das ciências, encontram-se mais de 30 livros, de sua autoria ou em colaboração; 300 trabalhos publicados em Revistas do país e do estrangeiro, filme científico do qual é autor e coordenador de produção; mais de 1.000 artigos de jornalismo científico e outros.

Além de dedicar-se à docência a nível de graduação e em especial à pós-graduação, atendendo a cientistas procedentes de muitos países, ministrou cursos de natureza diversa, aulas, palestras e conferências no Brasil e no exterior, versando sobre temas variados do seu vasto domínio, os quais se aproximam da casa dos 1.000 .

Ao longo de sua brilhante carreira, a par do cumprimento de intensa programação de trabalho, tem participado de eventos científicos múltiplos e pertence a Associações Médicas nacionais e internacionais de relevância.

Foi agraciado com numerosos Prêmios, Medalhas e Honrarias no Brasil e no Exterior, afigurando-se entre eles, a Medalha RHODA BENHAM, oferecida pela Associação de Micologia Médica das Américas, o "Prêmio José Reis de Divulgação Científica - 1982", outorgado pelo CNPq.

$\mathrm{Na}$ Universidade de São Paulo, exerceu entre outras, as funções de Pró-Reitor, Diretor da Faculdade de Medicina e da Escola de Enfermagem, sempre deixando legados valiosos em benefício da Instituição e do fomento da docência, da pesquisa e da extensão à comunidade.

orgãos criados pelo Professor Lacaz são modelos para o mundo como por exemplo o Instituto de Medicina Tropical, Museu Ceroplástico e o Laboratório de Micologia Médica, este último, Centro de Referência nessa matéria para a América Latina.

Professor Lacaz exerceu ainda o alto cargo de Secretário de Higiene e Saúde de São Paulo, de 1971 a 1973, ocasião em que prestou relevantes serviços ao povo paulista, entre eles: a fundação da Maternidade Vila Nova Cachoeirinha, ampliação da rede de Postos de Saúde, extensão de cobertura de serviços à população carente.

Cálculo nenhum sobre as realizações do eminente homenageado, por mais generoso que fosse, poderá espelhar a realidade, tamanha a magnitude do impacto sócio-científico-cultural e a dimensão humanística de 
suas obras, tornando-se desnecessário nos determos ainda mais em dados do seu riquíssimo "Curriculum Vitae".

$E$, contudo, indeclinável dever, cultuar, ao lado de inconteste valor como médico, cientista e educador, as extraordinárias virtudes, entre outras, morais e humanisticas que o conduziram a apoiar o desenvolvimento de outras áreas da Saúde, mormente da Enfermagem e em particular, da Escola de Enfermagem da Universidade de São Paulo.

Desde sua criação em 1942, a Escola vem contando com a colaboração do Professor Lacaz como docente de Microbiologia e Imunologia e incentivador da Enfermagem cientifica.

No quadriênio 1978-1982, como Diretor, estimulou o nascimento de uma nova era na história desta Escola, marcada pela sua projeção além dos horizontes da Enfermagem.

Tão logo assumiu a direção, Professor Lacaz, com aguçada sensibilidade e visão futurista percebeu estar a Instituição, intrinsecamente amadurecida o suficiente para se colocar na vanguarda da Enfermagem brasileira, incipiente, no entanto, nas relações de engajamento de fato, na comunidade acadêmica.

Feito o diagnóstico, procurou implementar estratégias para imprimir à estrutura e ao funcionamento da Escola, as características essenciais para assegurar vida acadêmica forte e autônoma, compatível com a dinâmica de intercâmbio e integração com as demais Unidades da Universidade de São Paulo, outras universidades, associações científicas e órgãos de Saúde e Educação.

Como registra o Relatório da gestão do Professor Lacaz apresentado à Congregação da Escola de Enfermagem e ao Magnífico Reitor da Universidade de São Paulo, entre as metas atingidas constam: organização de Serviços e Setores de apoio logístico à área Administrativa e Acadêmica; Indicação de numerosos Grupos de Trabalho para estudo dos problemas maiores da Unidade tais como a Produção Científica, Criação do Quadro Docente e Estrutura Organizacional, bem assim das questões pertinentes à reorientação do Sistema de prestação de serviços de saúde e formação de recursos humanos; Incentivo e apoio aos Cursos de Mestrado e Doutorado, este iniciado em 1982 em colaboração com a Escola de Enfermagem de Ribeirão Preto, constituindo-se no primeiro Programa de Doutorado, na área, na América Latina e Caribe.

O plano acadêmico foi favorecido com a obtenção de recursos para a passagem gradativa de docentes de RTP para RTC e RDIDP; efetivação de dois concursos de Professor Titular e dois de Livre-Docência; Criação de Serviços de Assistência Nutricional e de Doenças Transmissíveis; apoio ao Hospital Universitário, à Biblioteca e à participação do corpo docente em grupos multiprofissionais.

Considerando importante cultuar o passado e edificar a memória da Escola de Enfermagem da Universidade de São Paulo, às quais se ligam ilustres nomes como Florence Nightingale, Ana Neri, Glete de Alcântara, Carlos Chagas, Oswaldo Cruz, Wanda Horta, Edith Fraenkel e Maria Rosa Sousa Pinheiro, estas últimas, respectivamente $1^{*}$ e $2^{4}$ Diretora 
desta Escola, instituiu, a "Galeria dos "Grandes Vultos" da Enfermagem", e tornou realidade a publicação do livro sobre a "história desta Escola".

Aos discentes também não faltou apoio.

Foi concedida nova sede para o Centro Acadêmico XXXI de Outubro, mais ampla e com melhores condições e criados sete cargos de "Aluno-Monitor" junto a diversas disciplinas. O Departamento Científico do Centro Acadêmico recebeu, constante estímulo e orientação na organização de palestras e cursos.

Defensor dos interesses da Escola de Enfermagem, lutou pela sua autonomia, e já quando da desanexação da Faculdade de Medicina, em 1963, Professor Lacaz propiciou oportunidades de aprimoramento em Ciências Básicas, para docentes desta Casa.

Possibilitou que seu sucessor fosse, pela vez primeira, uma docente da própria Unidade, a Professora Doutora Leda Ulson Mattos que vem, desde dezembro de 1982, dirigindo os destinos desta Casa, de forma segura e hábil.

Ao se despedir da direção da Escola de Enfermagem, Professor Lacaz deixou, além de saudade e reconhecimento, discípulos que procuram honrá-lo e julgam um dever, seguir os ensinamentos do sábio Mestre.

$O$ respeito da Comunidade de Enfermagem para com o Professor Lacaz tem sido explicitado em diversas solenidades por renomadas personalidades, entre elas, a saudosa Professora Doutora Wanda de Aguiar Horta, a primeira enfermeira desta Escola a conquistar o grau de Professor Titular, que em seu discurso de posse, assim pronunciou:

"Com os professores e colegas, muito aprendi; exemplos e modelos marcaram-se indeléveis, em meu ser, dentre eles o da figura saudosa de D. Edith Magalhães Fraenkel, Dra. Haydée Dourado, D. Maria Rosa Sousa Pinheiro e de muitas outras.

Dentre os professores, em particular, o Professor Carlos da Silva Lacaz. Através de seu entusiasmo contagiante, aprendi que só podemos ensinar aquilo em que acreditamos, amamos, conhecemos e vivenciamos. Também o respeito mútuo, a simplicidade e, ao mesmo tempo, a camaradagem e amizade. Não éramos para ele, mais uma turma de alunos, éramos Gente: Gerci, Olinda, Zélia, Gigi, Wanda...".

Ao inaugurar este Retrato, orgulhosa está a Escola de Enfermagem em legar aos pósteros a imagem sempre presente do exemplo de virtude, justiça, luta, tenacidade, responsabilidade e de coragem indômita para enfrentar os desafios da ciência e da humanidade, a fim de que lhes possa servir para nortear e confortar o árduo caminhar pela estrada da vida.

Parafraseando o Professor Newton Guimarães, em seu discurso de saudação ao Professor Lacaz, "não faz jus ao diploma, o médico brasileiro que não conhecesse Lacaz", poder-se-ia declarar "não faz jus ao diploma, o enfermeiro brasileiro que não conhecesse o Professor Doutor Carlos da Silva Lacaz".

Ao grande Mestre, nossa eterna gratidão. 